\title{
História, memória e identidade: refletindo sobre a oralidade como aporte para leitura de uma cultura
}

\author{
History, memory and identity: reflecting on orality as a \\ contribution to reading a culture
}

\author{
Enviado em:03/10/2017 \\ Aceito em: 14/01/2018 \\ CANABARRO, Ivo Dos Santos ${ }^{1}$ \\ MOSER, Lilian Maria ${ }^{2}$ \\ ERNESTO, Eduardo Servo ${ }^{3}$
}

\begin{abstract}
Resumo:
Este artigo socializa parte da reflexão sobre História, Memória e Identidade à luz dos posicionamentos de Montenegro (2012), Halbwachs (2003), Tedesco (2004) e Hall (2012). Com base nesse estudo, buscou-se problematizar, no desenvolvimento deste trabalho, a questão de os sujeitos, ao narrarem suas trajetórias de vida, revelarem significações e representações culturais construídas e compartilhadas no âmbito de uma memória social, em correlação direta com sua cultura. O resultado dessa reflexão possibilitou a construção de um conhecimento sobre como a Oralidade se constitui uma ferramenta metodológica para a leitura de uma dada cultura.
\end{abstract}

Palavras-chave: História; Oralidade e Memória; Identidade.

\begin{abstract}
:
This article socializes part of the reflection on History, Memory and Identity in light of Montenegro's (2012), Halbwachs' (2003), Tedesco's (2004) and Hall's (2012) positioning. Based on this study, we attempted to discuss, in its development, the matter of subjects, when they describe their life stories, revealing meanings and built and shared cultural representations within a social memory, in direct correlation with their culture. The result of this reflection led to the construction of knowledge
\end{abstract}

\footnotetext{
${ }^{1}$ Doutorado em História pela Universidade Federal Fluminense (UFF), Pós doutorado em História Social pela Universidade Federal Fluminense. Professor da Universidade Regional do Noroeste do Estado do Rio Grande do Sul

2 Doutorado em Desenvolvimento Sustentável (UFPA). Atualmente é professor titular da Universidade Federal de Rondônia.

3 Mestre em História e Estudos Culturais. Membro do centro de estudos avançados em memória e Patrimônio de Rondônia - CDEAMPRO.
} 
about how Oral Tradition constitutes a methodological tool for reading a given culture.

Keywords: History; Oral Tradition and Memory; Identity.

\section{Introdução}

Com este trabalho tem-se a pretensão de apresentar algumas considerações a respeito de como a oralidade, enquanto metodologia, pode servir de um instrumento eficaz para pesquisadores das Ciências Humanas problematizarem uma determinada dimensão cultural. Sob esse viés, compreende-se que pensar a Oralidade é um exercício para pensar a Memória e a Identidade. Como também demostrando como as práticas de significações e representações são institucionalizadas na memória social, em processo capaz de ser decodificado por pesquisadores, que buscam fazer uso da luz da oralidade como metodologia para estudar uma dada cultura.

$\mathrm{Na}$ construção do conhecimento, no referido trabalho, buscaram-se os respaldos em autores que norteiam os elementos teóricos de uma determinada pesquisa, podemos destacar quatro conceitos fundamentais: o de cultura, uma vez que se tenta compreender práticas culturais em circulação em dado grupo social; o de representação para se entender a significação de práticas estabelecidas a patir de laços sociais; o de identidade, pela importância de se compreender a maneira como dado grupo compõe visões de mundo e a compartilha; e o de memória, para se entender como representações estabelecem laços de continuidade em um dado grupo.

Destaca-se como referência a noção de Identidade, formulada por Stuart Hall (2012), em que as identidades sociais são construídas a partir de representações dentro de discursos culturais; que informam como um dado grupo vive e compartilha seus significados. Neste sentido, se relaciona à centralidade da cultura na constituição da subjetividade, da própria identidade, e da pessoa enquanto ator social. O mesmo autor, entende cultura; como um discurso de existência e de práticas sociais, isso dependente de um dado significado para "produzir efeitos" dentro deste mesmo discurso. Em outras palavras, significa dizer que as identidades culturais, são construídas dentro de processo interior de representação, sendo inerente à própria cultura e não externa a ela. 
Em um derteminado diálogo complementar a essa ideia, Halbwachs (2003) mostra que a Memória; pode ser também um processo de construção configurada na relação do sujeito com instituições sociais: como a família, a igreja, a escola, dentro outras. No mesmo sentido, esta possui um caráter social e é expressa pela linguagem, narrando determinações sociais variadas que formam o sujeito com determinadas visões de mundo.

$\mathrm{Na}$ mesma perspectiva narrativa, as representações culturais que estão vivas na memória de um grupo social podem se atualizar no presente. As mesmas são reconstruídas/reelaboradas, constituindo-se parte da identidade de um grupo, dado que possibilitou, neste estudo, a reflexão sobre a abordagem da oralidade enquanto metodologia. Sendo assim, (MONTENEGRO, 2012), no sentido de propiciar uma forma de compreensão dessas reinterpretações de modo de vida, uma vez que, ao serem recriadas, se revestem de temporalidade e podem ser historicizadas em diferentes contextos de pertencimento.

Tomando como base esse viés de abordagem, compreende-se que a experiência humana; enquanto práticas culturais, permeiam um cotidiano que se faz parte constituinte dessa reconstrução e, pensando assim, o pesquisador em ciências humanas pode refletir a reconstrução de cotidianos por grupos sociais. Nesta perspectiva, pode-se pensar partir do que Tedesco (2004) chama de materialidade da experiência, enquanto representações culturais, lembrança, memória e símbolos.

Neste sentido, o historiador de forma interdisciplinar, pode pensar essa questão através da oralidade, percebendo justamente como, a partir dessas representações, grupos humanos constroem socialmente seu mundo. Sendo assim, a história cultural para (BURKE, 1992), dentro de sua proposta de não exclusividade de uma verdadelinguagem sobre o passado, pode ajudar pesquisadores a compreender outras experiências sobre o passado, justamente como mais uma possibilidade de análise desse mundo cultural reconstruído por grupos sociais em diferentes contextos e culturas.

\section{Memória, Signos e Representações Culturais: a Memória Coletiva}

A História, a partir da década de setenta do século $X X$, tem se dedicado ao estudo da memória; para pensar, por exemplo, os movimentos políticos, a cultura

Revista Memória em Rede, Pelotas, v.10, n.18, Jan./Jul.2018 - ISSN- 2177-4129 
popular, o cotidiano e demais dimensões históricas. A preocupação como ela sempre foi presente no campo das ciências humanas, bastando olhar o primeiro debate no âmbito da historiografia desde a antiguidade, quando por volta do século $\mathrm{V}$ Heródoto e Tucídides, historiadores gregos ${ }^{4}$, problematizaram, com os instrumentos analíticos de seu tempo, a subjetividade e a possível veracidade da memória para a construção do conhecimento histórico. Heródoto já afirmava que o testemunho histórico se esgotava na terceira geração; Tucídides, pensando próximo, fragilizava e desconfiava da memória, dizendo que seria incapaz de garantir fidelidade ao relato da realidade.

$\mathrm{Na}$ Contemporaneidade, os instrumentos metodológicos e a problematização em relação à memória como objeto de estudo mudaram muito, são os mais variáveis possíveis. Os estudos dela, no âmbito da historiografia, em geral são de forma interdisciplinar, com a antropologia, a sociologia e mesmo, a psicanalise, têm auxiliado na compreensão de temporalidades e experiências, ou seja, de como o cotidiano configura-se com uma construção social, por meio de formas simbólicas e representações. Sendo assim, neste trabalho, visualiza-se que o estudo da memória de um grupo, liga-se diretamente ao que Stuart Hall (2012) chama de centralidade cultural, que gera significações, representações e identidade entre um grupo social.

Neste viés de abordagem, as memórias podem ser pensadas como um processo de manutenção do "eu", conforme (CANDAU, 2012), podendo-se entender que é por meio da retrospecção que o indivíduo, dentro de um dado grupo, mantém seus símbolos e sua cultura. A partir disso, pode-se fazer uma série de reflexões no âmbito da mesma e também da identidade, aspectos abordados no estudo em questão. O tema abordado pode também ser estudado, no âmbito dos estudos culturais $^{5}$, não apenas enquanto prática de pesquisa, mas também como elemento teórico para se pensar o compartilhamento de significados dentro de uma dada cultura. Ainda pode-se acrescentar que, ao demonstrar o caráter social da memória, justamente porque se liga ao compartilhamento de cultura. Sendo assim, é possível correlacionar com outros autores como Halbwachs (2006) e Tedesco (2004).

\footnotetext{
${ }^{4}$ Para aprofundar este elemento, ver: COLLINGWOOD (1972)

${ }^{5} \mathrm{O}$ termo Estudos Culturais - EC pode ser usado para se referir a uma forma de se fazer pesquisa acadêmica, na qual a cultura é discutida e analisada a partir de múltiplos aspectos, privilegiando a interdisciplinaridade, bases epistemológicas do Birmingham Centre For Contemporary Cultural Studies, com gênese na Inglaterra no segundo pós-guerra, grupo que utilizando essas bases se propôs a pesquisar uma chamada cultura de "maioria" em contraposição a uma cultura de minoria e elitista que comumente era referência, até então, para produção cultural naquele país. (EDGAR, SEDGWICK, 2003)
}

Revista Memória em Rede, Pelotas, v.10, n.18, Jan./Jul.2018 - ISSN- 2177-4129 
No que diz respeito à Memória e Estudos Culturais, afirma-se que a primeira é um elemento de leitura, que pesquisadores no âmbito da cultura têm chamado de Identidade, nesta última década. No mesmo sentido, Stuart Hall (2012), um dos grandes nomes dos Estudos Culturais, ao falar sobre identidade afirma que este termo, por se ligar a manifestações humanas, não possui uma definição sintética ou única, acrescentando que ele não paira no "ar", pois é uma construção a partir de representações culturais e signos, elementos que, de alguma forma, geram a identidade que se liga a uma dada centralidade cultural.

Essa mesma perspectiva de construção da identidade, como diz Tedesco (2004), não é algo contínuo, uma vez que ela se dá pouco a pouco, com base na experiência vivida, rememorada, retida anteriormente e sintetizada, construída ou reconstruída. E é em virtude disso que a memória é um componente essencial para a identidade, uma vez que está correlacionada ao compartilhamento de uma cultura, sendo assim, ela é uma representação social entre indivíduos, conforme suas palavras.

\begin{abstract}
Por isto a memória está ligada a um papel importante no mundo social, a de conservar informações psíquicas capaz de atualizar impressões passadas, assim como representações sociais que são naturalizadas do cotidiano de um grupo, informando ainda a estes indivíduos inseridos em uma coletividade o sentido de sua própria colocação no tempo, interligando o passado ao presente. (TEDESCO, 2004, p. 31).
\end{abstract}

No aprofundamento dessa questão, pode-se afirmar; que as memórias de grupos sociais possuem quadros de significação, com estratégias, simbologias, representações, experiências da vida cotidiana que criam temporalidades e espacialidades. Essas visões de mundo se ligam ao que Hall (2012) chama de centralidade cultural, sendo por isso que ela gera pertencimento entre os membros de um mesmo grupo que compartilham sua significação, resultando a identidade, justamente enquanto uma forma simbólica, porque se "veem" como iguais, por compartilharem uma mesma visão de mundo.

Ainda para Halbwachs (2003), a memória é um instrumento social, é sempre uma construção coletiva. Em sua obra $A$ memória Coletiva, o autor defende a teoria a respeito de como os grupos humanos constroem significações a partir de seu cotidiano, e, coletivamente, as compartilham. Para esse autor, isso se liga à cultura e aos fatores psicossomáticos em relação à transmissão dessas informações pelos 
neurônios $^{6}$. Sendo assim, a sua teoria se concentra em expor o movimento dela e, constituindo uma tentativa de construção do passado a partir de uma reflexão do presente, em relação ao que deve ser silenciado e o que deve ser lembrado por um grupo.

Pode ser considerado válido dizer, que a obra de Halbwachs (2003), é de suma importância para se analisar questões de identidade. Quando esse autor concentra sua análise na memória, refletindo sobre como ela é compartilhada em uma dada coletividade, em um tempo e um espaço, mostra funções de identidade cultural, uma vez que revela que o grupo pensa um passado a partir de um presente e, ao mesmo tempo pensando no futuro; é o passado como uma forma de transmissão de significações e tradições que se ligam a centralidade cultural do grupo que compartilha tais sentimentos e representações.

Halbwachs (2003) mostra, então, como as lembranças de um grupo trazem noções de localização e temporalidade como a forma da casa, os móveis, a forma de expressão da religião que são experiências que se ligam ao cotidiano do grupo. Também chama a atenção para o fato de que cada memória individual é um ponto de vista sobre a coletiva, e de que este ponto de vista muda conforme o lugar que se ocupa e as mudanças que esse espaço ocupado venha a sofrer. Sendo assim, estas possuem um caráter social, são expressas pela linguagem e narram as determinações sociais mais variadas. Ainda com base nesse autor, apresentam-se reflexões sobre a questão da memória coletiva e individual:

\begin{abstract}
É mais comum considerar-se a memória uma faculdade propriamente individual - ou seja, que aparece numa consciência reduzida a seus únicos recursos, isolada dos outros, e capaz de evocar, por vontade ou por acaso, os estados pelos quais passou antes. No entando, como não é possivel questionar o fato de que frequentemente reintegramos nossas lembranças em um espaço e um tempo sobre cujas divisões nos entendemos com os outros, de que nos situamos também entre datas que não tem sentido senão em relação aos grupos de que fazíamos parte (HALBWACHS, 2003, p. 76).
\end{abstract}

Sendo assim, a memória individual, para Halbwachs (2003), não existe sem a linguagem e seus códigos de leituras comuns ao grupo em que são compartilhados no ambiente social, com os quais os indivíduos exercem seus papéis sociais, de acordo

\footnotetext{
${ }^{6}$ Essa passagem faz referência à questão psicossomática em Halbwachs (2003), em relação a como esse autor constrói sua argumentação teórica. No entanto, dissertar sobre esse assunto não é o objetivo deste trabalho, o qual se concentra na questão da memória como instrumento de leitura e problematização de uma dada cultura.
}

Revista Memória em Rede, Pelotas, v.10, n.18, Jan./Jul.2018 - ISSN- 2177-4129 
com as regras socialmente estabelecidas. Sendo assim, para esse autor, a individual é um ponto de vista sobre os dados compartilhados coletivamente. A subjetividade de um indivíduo está diretamente ligada às formas de ver e sentir coletivamente e, por isso, a memoria coletiva, na forma de elementos socialmente contruídos, faz um corte transversal nas memórias de cada indivíduo que a compartilha.

Nas palavras do autor:

De bom grado, diríamos que cada memória individual é um ponto de vista sobre a memória coletiva, que este ponto de vista muda segundo o lugar que ali ocupo e que esse mesmo lugar muda segundo as relações que mantenho com outros ambientes. Quando tentamos explicar essa diversidade, sempre voltamos a uma combinaçao de influências que são todas de natureza social. (HALBWACHS, 2003, p. 70).

Ainda é possível perceber um caráter social na teoria de Halbwachs (2003), uma memória coletiva que se configura nas intituições sociais como família, igreja, escola, dentre outras, que formam o sujeito com determinadas visões de mundo. Para esse autor, a individual apóia-se na coletiva, uma vez que o indivíduo se insere nessa coletividade a patir de uma estrutura de sentido que o grupo compartilha. Percebe-se que Halbwachs, já no início do século $X X$, evidenciava não apenas o caráter coletivo da memória, mas também problematizava uma ideia de identidade ligada a social, a partir de uma espécie de comunhão do olhar, uma vez que afirmava, com base no que chamava memória coletiva, que indivíduos compartilham uma leitura de temporalidade e uma experiência cotidiana que dão sentido a um dado grupo.

Complementando essa idéia entende-se, então, que é a partir disso e do que Halbwachs (2003) chama de comunhão do olhar que surgem representações culturais, ou melhor, "representações coletivas", em que a experiência comum do indivíduo se liga a uma esfera de valores de grupo. Por extensão, Hall (2013) revela que as identidades culturais se formam, tendo uma base concreta justamente nessas representações, compartilhadas por um determinado grupo social, às quais, de uma forma mais ampla, se relacionam à centralidade da cultura na constituição da subjetividade, da própria identidade, e da pessoa enquanto ator social.

Então:

Por isto, quando um homem entra em sua casa sem star acompanhado por ninguém, sem dúvida durante algum tempo 'ele andou só', na linguagem corrente - mas ele esteve sozinho apenas em aparência, pois, mesmo nesse intervalo, seus pensamentos e seus atos se explicam por sua natureza de ser

Revista Memória em Rede, Pelotas, v.10, n.18, Jan./Jul.2018 - ISSN- 2177-4129 
social e porque ele não deixou sequer por um instante de estar encerrado em alguma sociedade. (HALBWACHS, 2003, p. 42).

A partir do que o autor expõe fica evidente, que quando um indivíduo se insere em uma coletividade, consequentemente, compartilha uma série de valores culturais. Nesse sentido, ao falar da importância da formação e do desenvolvimento da identidade do grupo e de um sentimento comum, tece conclusões a respeito de vínculos sócioculturais, justamente porque, ao serem institucionalizados, atuam como bens simbólicos.

Ainda numa mesma perspcetiva narrativa, acrescente-se que, para Candau (2012), existe uma forte ligação entre memória e identidade, especificamente no caráter das representações sociais trazidas por memórias coesas para continuidade/manutenção da identidade que acaba por permitir através da retrospecção a manutenção do 'que eu sou' (CANDAU, 20012, p. 22). E continua sua reflexão:

\begin{abstract}
A memória coletiva, por meio da narração, reafirma sua força de transmissão, pois, para continuar a recordar, é necessário que cada geração transmita o fato passado para que possa se inserir nova vida em uma tradição comum. $O$ ato narrativo, na medida em que é possível sua elaboração e apropriação, constrói um sentimento de identidade coletiva do grupo e um sentimento de pertencimento dos indivíduos. (CANDAU, 2012, p. 23).
\end{abstract}

É possível perceber dessa forma, que compartilhar uma memória comum e uma identidade com outras pessoas é uma forma que Tedesco (2004) chama de contratualidade cultural, pois para esse autor compartilhar significações em um grupo é, principalmente, uma relação de identidade que gera símbolos e cultura. A mesma é definida como um campo de conflito e tensão, de traços ocultos e fragmentos diversos. Muitas vezes os depoentes, ao institucionalizarem o que deve ser dito na forma de "uma verdade" acabam por justificar a ordem estabelecida em uma dada organização social. Sendo assim, a memória é um campo de construção do presente, na qual se manifesta um conjunto de representações que permitem conservar o que é memóravel, no sentido do que deve ser lembrado no presente.

\title{
Memória e Institucionalização: Comunhão do "ver"
}

$\mathrm{Na}$ perspectiva de se complementar a questão abordada, pode-se falar de memórias, chamar-se-á de institucionalização o que Anderson (1982) denomina de 
comunidade imaginária, representações e significações que indivíduos compartilham em comum, tendo por objetivo dar sentido ao presente desse sentimento compartilhado pelo grupo, que é uma espécie de interpretação institucional; é a construção de uma temporalidade que tem por função dar significação a esse presente referido, como a construção e a reprodução de uma "verdade", que chega ao pesquisador por meio da oralidade.

De outro lado ainda é perceptivel que ao utilizar-se-á mais uma vez a categoria de pensamento de Halbwachs (2003) que, ao dar um estatuto social à memória, acabou por refletir sobre a rememoração, compreendendo que o passado é uma construção do presente, mostrando a relação do homem com o tempo e sua própria identidade. Pode-se dizer, então, que para esse autor não existe passado em si, mas um passado construído/reconstruído pelo grupo, a partir de uma consciência dotada de sentidos, subjetividades, intencionalidades, relações de poder na construção de uma homogeneização do ver e pensar um determinado elemento da vida cotidiana. Dessa forma, para Halbwachs (2006 p.54), "comumente o indivíduo liga suas lembranças ao um espaço e a uma temporalidade em que dividiu com outros sentimentos em relação ao compartilhamento desta temporalidade".

Relativamente a essa percepção, acrescenta:

Não haveria nenhuma memória, pois nós só nos lembramos de fatos que têm por traço comum pertencer a uma mesma consciência, o que lhe permite ligar uns aos outros como variações sobre um ou alguns temas. (HALBWACHS, 2006, p. 100).

Numa perspectiva narrativa de Anderson (1982), essa institucionalização funciona a patir de dados ou de noções comuns que são compartilhados por um grupo e outros indivíduos também, o que só é possível em uma sociedade que compreende esses significados. Para que os sentidos se aproveitem da lembrança dos outros, não basta que esses apresentem seus testemunhos, também é preciso que existam muitos pontos de contato e identificações entre os mesmos, para que a lembrança coletiva venha a ser reconstruída sobre uma base comum compartilhada entre indivíduos na sociedade, sendo esse processo o compartilhamento desta homogeneização da memória coletiva.

Nesse mesmo viés de abordagem, a memória evoca inúmeras direções, como se a lembrança fosse uma baliza que permitisse situar variações nos contextos sociais e da experiência coletiva. É por esse motivo que elas possuem uma historicidade, 
justamente pela possibilidade de análise do tempo social institucionalizado por um grupo, sendo uma forma de o pesquisador perceber e refletir significações e representações de grupos sociais, a exemplo de um grupo social que passa pela experiência da migração que, em muitos momentos, é vista uma rememoração do tempo e da experiência de outrora no que o grupo compartilha em sua experiência social no presente.

A memória além de rememoração do passado é conhecimento histórico cultural, bastando olhar a afirmação já feita aqui de que a mesma experiências de um grupo social se correlaciona diretamente com sua identidade (TEDESCO, 2004). Dessa forma, um grupo, ao compartilhar significações que geram a identidade, possibilita o aparecimento de múltiplas experiêcias culturais e contrução de realidades.

\begin{abstract}
A ideia é de institucionalizar a memória de determinado grupo, o que implica reconhecimento e interesse em manter como sua memória. Segundo Gourarier, as estruturas materiais, uma vez instituídas como patrimônio, passam a dispor do estatuto de inviolabilidade, adquirindo caráter de verdade a ser reproduzida para toda a sociedade, podendo ser comparável a objetos sagrados. (TEDESCO, 2004, p 76).
\end{abstract}

A partir do exposto é possivel perceber disso, que se pensa a memória coletiva (HALBWACHS, 2003) como fundadora de uma temporalidade, uma estética, uma forma de construção social da realidade, que designa representações que geram identidade. Essa discussão leva a outra que Tedesco (2004) chama de Dimensão Fenomenológica da Memória, algo amplo, mas fundamental para se compreender a correlação entre memória e cultural. Partindo da afirmação de que a realidade social é um produto de interação e somatório de objetos da vida cultural e social de um grupo, surge, então, a manutenção e o compartilhamento de um mundo comum entre esses indivíduos, isso se manifestando em fins práticos no cotidiano, quando o grupo social compartilha significações em uma determinada experiência para manter uma lógica instaurada.

Sendo assim, pode-se afirmar que é justamente nessa esfera de compartilhamento que reside uma espécie de base de análise do social e do cultural, compreendendo-se como um grupo social constrói uma realidade, isso acontecendo na linguagem e nas práticas de significações, gerando, assim, o entendimento do que regula a vida de forma subjetiva, sendo o papel do pesquisador no âmbito de 
humanidades problematizar e compreender a significação dessas representações que indivíduos produzem em sua vida cotidiana.

As representações comuns e as tipificações estruturam atividades e significações que modelam 0 mundo do conhecimento comum. $O$ conhecimento que os indivíduos têm e podem ter de uns e outros é uma condição da vida social, mas também um saber sociologico. (TEDESCO, 2004, p. 52).

Nas observações do autor é possivel inferir, então, que o cotidiano é não apenas um regramento, uma rotina ou repetição, mas também representações e significações que estruturam e modelam um mundo comum. A memória, nesse quadro, é uma espécie de referência ao passado, contendo representações que formam uma temporalidade e, com essa percepção, memória e identidade estão diretamente correlacionadas, devido ao caráter de retrospecção e manutenção de significações.

Para complementar a discussão nessa abordagem afirma-se que quando se fala em experiência, aqui se pensa no "o processo que o indivíduo se apropria do vivido e o sintetiza" (TEDESCO, 2004, p. 98) ${ }^{7}$, pois se observado bem isso está correlacionado diretamente à memória, uma vez que os significados variados de experiência no vivido do grupo fornece matéria prima para vivenciar as experiências enquanto continuidade da consciência, reflexão que, mais uma vez endossa a reflexão de que a memória está diretamente ligada à identidade, na forma de manutenção de valores, símbolos e tradições, da vida coletiva de um grupo.

A abordagem direciona-se num sentido convergente em que, a memória está em consonância com o conjunto de representações culturais que ajudam a formar também noções temporais e identitárias. Essa identidade, em outras palavras, é um sistema articulado de ideias e imagens que existem em uma representação coletiva, formam o imaginário social de um grupo, na forma de uma interpretação do que passou e, em virtude disso, ao dizer de Halbwachs (2003), o passado, ao ser institucionalizado, pode ser inventado, manipulado segundo determinados fins, pois a experiência coletiva implica em selecionar e recordar.

\section{Pensando a Oralidade e a Memória.}

\footnotetext{
7 Tedesco (2004) afirma que o conceito de experiência é complexo. Para pensar esse termo, em seu trabalho utiliza a categoria de pensamento de Gademer (1983).
}

Revista Memória em Rede, Pelotas, v.10, n.18, Jan./Jul.2018 - ISSN- 2177-4129 
Pode-se afirmar que a memória enquanto retrospecção gera condições objetivas; na construção e reconstrução de um grupo social em relação a suas simbologias e significações culturais, constumes e identidade, compondo uma imagem de um passado que se correlaciona ao pensamento de uma sociedade, em um tempo e um espaço.

Num sentido complementar a oralidade é assim um instrumento capaz de ajudar a pensar o que Halbwachs (2003) chamou de memória coletiva. Essas significações presentes em mitos, simbologias, tradição popular, são parte de um processo geral da memória social, fazendo brotar relações sociais, padrões de estruturação de um imaginário; a oralidade é, então, uma metodologia com ordenamentos filosóficos, que ajuda pesquisadores no ambito das ciências humanas a problematizar e a construir um conhecimento a respeito da cultura de um grupo social. Portanto, quando um indivíduo entrevistado e indagado sobre um dado objetivo/acontecimento, sua opiniao sobre o tema (subjetividade) terá uma forte conectividade com "verdades" compartilhadas coletivamente pelo grupo social em que esse se insere.

Sendo assim, ainda é perceptivel que após essa constatação, ficam evidentes, para o pesquisador, signficaçoes culturais compartilhadas na memoria social de um grupo a partir da narração do sujeito e, sendo assim, essas significaçoes podem ser desdobradas em diferentes objetivos de pesquisa e, em virtudade disso, entende-se que a oralidade é um instrumento importante na leitura de uma dada cultura. Como se disse no início desta abordagem, a oralidade de alguma forma está presente já há muito tempo na historiografia e, desde a antiguidade, sempre foi objeto de discussões, no que tange à confiabilidade e à autenticidade. Entretanto, foi a partir da década de sessenta, principalmente nos Estados Unidos e na Inglaterra, onde se disseminaram centros de estudos ligados aos Estudos Culturais, que ela ganhou uma maior discussão enquanto fonte de análise de pesquisas no âmbito da cultura.

Pode-se ainda afirmarm que em geral, essas pesquisas procuraram investigar grupos de minorias, que até então não tinham tido espaço em reflexões acadêmicas, como: mulheres, loucos, grupos étnicos e sexuais. De acordo com Tedesco (2004), a oralidade não é algo inacabado, por ser viva, é parcial e existe um diálogo entre-vistas, no sentido de levar o pesquisador a refletir sobre a subjetivdade do sujeito narrante. 


\begin{abstract}
O termo 'história oral' indica um conjunto de pesquisas e de debates sobre a crítica histórica específica que se pode aplicar às fontes orais na sua possibilidade de ampliação cientifica e democratização (alargamento não só da gama de objetos históricos considerados, mas tambem do público que a história pode abarcar) e o uso, tipo e tendências de fontes são mais adaptadas. (TEDESCO, 2004, p. 113).
\end{abstract}

Nesta linda de abordagem escolhida o autor complementa que dessa forma, é um campo hermenêutico para se pensar a cultura, uma vez que possui instrumentos que possibilitam uma reflexão na esfera de como grupos sociais constroem um vivido através de mediações simbólicas. Sendo assim, a oralidadade ajuda a refletir sobre como os sujeitos, por meio de suas falas, ou melhor, de suas narrações, com base nas perguntas feitas, interpretam e constroem seu mundo por meio da linguagem, dandoIhe um signifcado. Reconnhecer a mesma na pesquisa é reconhecer também todo um universo simbólico de tradições presentes nas manifestações humanas.

O simples ato de recordar não é algo automático, mecânico, ou contínuo; a leitura de Montenegro (2012) mostra que a oralidade é uma prática discursiva e é, no momento da entrevista, por meio de uma pergunta, que o sujeito, a partir de sua singularidade em conectividade com o grupo, constrói suas lembranças, estabelecendo um diálogo entre presente e passado. Ainda com base na categoria de pensamento do mesmo autor afirma que sobre ela: é importante observar que em nenhum momento o objetivo do pesquisador deva ser o de "provar o vivido" em relação às falas dos entrevistados, mas justamente o contrário, visto que a narração do entrevistado é uma construção ligada a sua percepção de mundo, a forma como vivencia e constrói sua realidade a partir de um compartilhamento de significações.

Ainda na mesma perspectiva analítica de Montenegro (2012), é justamente por isso que esse autor, em seus estudos sobre a categoria de pensamento de Foucault, revela que a fala de um sujeito, assim como um texto, possui ordenamentos como descritivismo e subjetivismo que operam igualmente na construção dessa fonte e, dessa forma, o passado, na oralidade de um entrevistado, é uma construção, respondida a partir de significações e representações contidas no presente.

Ao se pensar sobre a presença do pesquisador na entrevista, não se pensa que essa ação é neutra, pois, de acordo com Albuquerque (2007), escrever a história é medir, e exercer função de traduzir a cultura, assim, não se tem o posicionamento teórico metodológico de "capturar o passado" ou "resgatar o passado", mas o objetivo

Revista Memória em Rede, Pelotas, v.10, n.18, Jan./Jul.2018 - ISSN- 2177-4129 
é outro: é valorizá-lo justamente como uma construção ligada a discursos, sistematizações a cerca das significações culturais que são compartilhadas pelo grupo ao qual o entrevistado está inserido.

Ainda seguindo a mesma lógica de pensamento foi possivel constatar que cada sujeito narrante possui sua singuralidade e subjetividade. Sendo assim pode-se afirmar que a oralidade é, então, uma oportunidade de pensar essas personalidades individuais inseridas dentro de sua cultura, como em meio à valorização da família, do trabalho, da ética de grupo, da religiosidade e mais uma vez chegando-se à identidade, ou seja, a problematização de como os atores sociais estabelecem a relação do passado com o presente.

\begin{abstract}
Os rituais, os símbolos, os mitos, as comemorações e os contos são linguagens "refrescadoras" do tempo da memória, do tempo histórico, do tempo passível de receber ressignificação. Esses elementos narrativos do tempo, espaço e experiência (os quais ligam memória com identidade) tem o poder de entrecruzar temporaldiades, de dialetizar presença/ausência, de contextualizar a interpretação histórica, de projetar, problematizar, temporalizar o futuro (pespectivar) a memória. (TEDESCO, 2004, p.116).
\end{abstract}

A partir do exposto foi possível perceber que, a partir do referencial teóricometodológico, a memória não é apenas um dado histórico, uma forma de cronologia, devendo-se pensar além do que é descrito como verdade pelo sujeito narrante, refletindo o passado descrito como uma construção a partir de um complexo de relação com as representações e significações do grupo de quem narra. Mais uma vez a saída é compreender como ela está ligada àquilo que Hall (2012) chama de centralidade cultural e Halbwachs (2003), de memória coletiva, enquanto um campo amplo e complexo de linguagens compartilhadas no âmbito de uma cultura.

Para finalizar a linha de abordagem, compreende-se que oralidade se correlaciona com a proposta dos Estudos Culturais enquanto estudo de uma cultura, na forma de um campo de pesquisa acadêmico. A mesma pode ser entendida como sendo uma fonte viva, permite que sujeito narrante torne-se um decifrador de sinais visíveis da construção de seu mundo. Ao dizer de Jonhson (2010), essa subjetividade é uma das maiores características dos estudos culturais britânicos ligados ao Birmingham Centre For Contemporary Cultural Studies.

\title{
Considerações Finais
}

Revista Memória em Rede, Pelotas, v.10, n.18, Jan./Jul.2018 - ISSN- 2177-4129 
A partir das reflexões propostas neste trabalho, refletiu-se, ao longo do texto, com base nos autores que tratam sobre o tema História, memória, identidade e oralidade, sobre possibilidades que pesquisadores no âmbito das Ciências Humanas interpretarem significações e representações culturais de um dado grupo social que dialogam com a cultura desses grupos. Sendo assim, nesse processo destaca-se o claro papel da memória que, de acordo com este estudo, caminha junto com a identidade, sendo parte constitutiva do processo sociocultural de se reviver simbologias, funcionando como retrospecção e fazendo o "quem sou" se atualizar no presente.

Por um lado, foi possível constatar que a oralidade se constitui, assim, um aporte para reflexões sobre objetos que pensam a construção e reconstrução de temporalidades, enquanto elementos estéticos que são valorizados por um grupo. Dessa forma, o entrevistado, em um jogo do que se discutiu neste trabalho como institucionalização da experiência, apresenta sua personalidade ligada a essas significações compartilhadas na memória coletiva de seu grupo, mostrando que a singularidade de cada biografia liga-se também a marcas carregadas socialmente.

Por outro lado, do mesmo processo a oralidade permite então inúmeras leituras socioculturais, leituras essas que se ligam às representações e significações que dialogam diretamente com a centralidade cultural dos entrevistados. Sem dúvida, essa percepção metodológica da oralidade remete a uma dimensão interdisciplinar, o casamento proveitoso com outras disciplinas como a sociologia e a antropologia, justamente para se perceber como o sujeito narrante constrói seu passado a partir de práticas de representações e significações compartilhadas por um grupo no presente.

A abordagem descritiva e a analítica nos permite afirmar que, oralidade aqui foi defendida como aporte capaz de propiciar, para pesquisadores da cultura, reflexões sobre o que Hall (2012) chama de centralidade cultural, de como grupos sociais criam significações para compreender e apreender objetos culturais. A partir do rol de autores apresentados neste trabalho, os quais refletem a respeito da memória sob um viés coletivo, pensou-se nela como um instrumento de aporte na leitura de uma cultura, todavia, em nenhum momento, afirmou-se que a subjetividade de um sujeito narrante não é importante para compreensão de um objeto cotidiano.

Pode-se afirmar que, sujeitos constroem muitas vezes estratégias para elaborar uma divergência com o coletivo, mesmo que de forma privada, todavia a

Revista Memória em Rede, Pelotas, v.10, n.18, Jan./Jul.2018 - ISSN- 2177-4129 
própria oralidade pode ser também elemento metodológico para compreensão de tais estratégias. Neste trabalho, o diálogo autores tornou evidente a compreensão e problematização de aspectos da memória de um dado grupo social, entendendo aquilo que esse grupo cria como verdades institucionalizadas sobre um dado acontecimento que envolve, transversalmente, todos desse grupo. E, a partir disso, um pesquisador, ao utilizar a oralidade como aporte, não deve visar o "resgate" de fatos do grupo a qual estuda, mas compreender uma dada configuração do cotidiano desse grupo, justamente a partir da leitura de sua cultura, um processo socialmente construído, através de práticas de significações e representações compartilhadas coletivamente.

\section{Referências}

ALBUQUERQUE. Durval Muniz Júnior de. A arte de Inventar o Passado. Bauru, SP: EDUSC, 2007.

ANDERSON, Benedict. Nação e consciência nacional. São Paulo: Ática, 1982.

BURKE, Peter (org.). A escrita da história - novas perspectivas. São Paulo: Edunesp, 1992.

CANDAU, Joel. Memória e Identidade. Trad. Maria Letícia Ferreira. São Paulo: Contexto, 2012.

COLLINGWOOD,R.G. A idéia de História. Editora Presença: Lisboa, 1972.

EDGAR, Andrew \& SEDGWICK Peter. Teoria Cultural de A a Z : Conceitos - Chave para entender o mundo contemporâneo. São Paulo : Contexto, 2003.

GADEMER, H. G Verità e método. Milano : Bompiani, 1983.

HALBWACHS, Maurice. A Memória Coletiva. São Paulo: Centauro, 2003.

HALL, Stuart. Da Diáspora, identidades e mediações culturais. Belo Horizonte: UFMG, 2012.

JOHNSON, Richard. O que é afinal os estudos culturais?. Belo Horizonte: Autentica, 2010.

MONTENEGRO Antonio Torres. História Oral, desigualdades e diferenças. Editora da UFPE; e UFSC, Recife: 2012.

TEDESCO, João Carlos. Nas Cercanias da Memória: temporalidade, experiência e narração. Caxias do Sul: EDUCS, 2004. 